\title{
Human Placenta Hydrolysate Promotes Liver Regeneration via Activation of the Cytokine/Growth Factor-Mediated Pathway and Anti-oxidative Effect
}

\author{
Tae Hee Lee, ${ }^{a, \#}$ Dong Sun Park, ${ }^{b, \#}$ Ja Young Jang, ${ }^{a}$ Isaac Lee, ${ }^{a}$ Jong Man Kim, ${ }^{c}$ Gyu Seong Choi, ${ }^{c}$ \\ Chang Taek Oh, ${ }^{c}$ Jeom Yong Kim, ${ }^{d}$ Hae Jung Han, ${ }^{d}$ Beom Seok Han, ${ }^{a}$ and Jae Won Joh ${ }^{* c}$ \\ ${ }^{a}$ Hoseo Toxicological Research Center, Hoseo University; Asan 31499, Korea: ${ }^{b}$ Department of Biology Education, \\ Korea National University of Education; Cheongju 28173, Korea: ${ }^{c}$ Department of Surgery, Samsung Medical Center, \\ Sungkyunkwan University School of Medicine; Gangnam-gu, Seoul 06351, Korea: and ${ }^{d}$ Research \& Development \\ center, Green Cross WellBeing Corporation; Bundang-gu, Seongnam 13595, Korea. \\ Received September 13, 2018; accepted December 20, 2018
}

Liver regeneration is a very complex process and is regulated by several cytokines and growth factors. It is also known that liver transplantation and the regeneration process cause massive oxidative stress, which interferes with liver regeneration. The placenta is known to contain various physiologically active ingredients such as cytokines, growth factors, and amino acids. In particular, human placenta hydrolysate (hPH) has been found to contain many amino acids. Most of the growth factors found in the placenta are known to be closely related to liver regeneration. Therefore, in this study, we investigated whether hPH is effective in promoting liver regeneration in rats undergoing partial hepatectomy. We confirmed that cell proliferation was significantly increased in HepG2 and human primary cells. Hepatocyte proliferation was also promoted in partial hepatectomized rats by $\mathrm{hPH}$ treatment. $\mathrm{hPH}$ increased liver regeneration rate, double nucleic cell ratio, mitotic cell ratio, proliferating cell nuclear antigen (PCNA), and $K_{\mathrm{i}}-67$ positive cells in vivo as well as interleukin (IL)-6, tumor necrosis factor alpha (TNF- $\alpha$ ), and hepatocyte growth factor (HGF). Moreover, Kupfer cells secreting IL-6 and TNF- $\alpha$ were activated by hPH treatment. In addition, hPH reduced thiobarbituric acid reactive substances (TBARs) and significantly increased glutathione (GSH), glutathione peroxidase (GPx), and superoxide dismutase (SOD). Taken together, these results suggest that hPH promotes liver regeneration by activating cytokines and growth factors associated with liver regeneration and eliminating oxidative stress.

Key words liver regeneration; placenta; partial hepatectomy; cytokine; anti-oxidative stress

\section{INTRODUCTION}

The liver plays a central role in metabolic homeostasis because it is responsible for the metabolism, synthesis, storage, and redistribution of nutrients such as carbohydrates, fats, and vitamins. ${ }^{1,2)}$ Hepatocytes perform most of the functions of the liver. Moreover, the liver is a unique organ that has the ability to grow and regenerate. ${ }^{3)}$ Although adult hepatocytes are long-lived and do not undergo cell division under normal conditions, the proliferative capacity and adaptive abilities of hepatocytes exist even under different metabolic conditions and in the event of hepatic resections or living donor liver transplantation. ${ }^{2,4)}$ These cellular activities and adaptive ability are promoted with decreased volume of liver tissue. ${ }^{5}$ When this fundamental proliferative ability is not sufficient to compensate for the resected liver, postoperative liver failure occurs, which is a serious complication and remains an important clinical problem. ${ }^{6}$ To overcome this issue, therapeutic methods that support liver regeneration must be explored. However, few treatment options are capable of enhancing liver regeneration in clinical settings, despite widespread interest and numerous trials. ${ }^{7)}$

The placenta is a rich source of many biological components, including hormones, cytokines, chemokines, and

\footnotetext{
\# These authors contributed equally to this work.

* To whom correspondence should be addressed. e-mail: jw.joh@samsung.com
}

growth factors. ${ }^{8,9)}$ Many of these factors possibly act in an autocrine and/or paracrine fashion within the human placenta and regulate the production of other biologically active substances, which may hold potential for therapeutic agents as suggested in previous studies, where fractions of human placenta hydrolysate $(\mathrm{hPH})$ stimulated tissue repair processes. $^{10,11)}$ Over the last few decades, hPH has been prescribed clinically to treat chronic hepatitis, ${ }^{12,13)}$ liver cirrhosis ${ }^{14)}$ and other hepatic diseases. ${ }^{15)} \mathrm{hPH}$ reportedly ameliorated hepatic injury through liver regeneration ${ }^{9)}$ and inhibited inflammatory reactions and apoptosis. ${ }^{16)}$ Kong and Park recently reported that injection of hPH improved the health status of elderly Koreans. ${ }^{17)}$ Moreover, hPH decreased the levels of serum transaminases (aspartate aminotransferase (AST) and alanine aminotransferase (ALT)). ${ }^{8}$ ) Although pseudolobule formation caused by $\mathrm{CCl}_{4}$ was unaffected by $\mathrm{hPH}$, intravenous injection of $\mathrm{hPH}$ minimized the lipid deposition and pathological changes. ${ }^{8)}$ In another study, the histological efficacy of $\mathrm{hPH}$ was better in obese patients than in non-obese ones, and no adverse events were observed during the study. ${ }^{12)}$ Because it is safe and well tolerated, the use of hPH was suggested to be potentially effective for the treatment of liver diseases However, the mechanisms underlying the therapeutic effects of $\mathrm{hPH}$ remain unexplored.

Although it has not yet been studied with specific growth factor or cytokine-regulated signal transduction pathways, 
many growth factors and cytokines have been implicated in the regulation of liver regeneration. ${ }^{2,4)}$ The growth factors include hepatocyte growth factor (HGF), epidermal growth factor (EGF), and transforming growth factors (TGFs), and the cytokines include tumor necrosis factor (TNF)- $\alpha$ and interleukin (IL)-6. ${ }^{18,19)}$ In animal models, in which hepatocytes are directly damaged and thereby induced to undergo necrosis, similar growth-factor- and cytokine-mediated pathways are activated as observed after partial hepatectomy (PHx). ${ }^{2,3)} \mathrm{Cir}-$ culating growth factors and cytokines that were present in the serum of hepatectomized rats induced hepatocyte replication in animals ${ }^{19,20)}$

Production of reactive oxygen species (ROS) can adversely affect liver regeneration. ROS regulate a number of signaling pathways that can affect liver regeneration. ${ }^{21)}$ It is also known that ROS mediates cell growth arrest ${ }^{22)}$ and activates cell cycle inhibitor proteins. ${ }^{23,24)}$ Thus, ROS production in the liver likely plays a role in the negative regulation of liver regeneration. Previous studies have shown that oxidative stress results from various factors during liver transplantation, indicating that oxidative stress inhibition may promote liver regeneration. ${ }^{25-27)}$

Based on these background data, we investigated the effects of $\mathrm{hPH}$, including the effects of various cytokines and growth factors, as well as the anti-oxidative effect of hPH on liver regeneration after $\mathrm{PHx}$. We also investigated the components of $\mathrm{hPH}$ and studied the mechanisms underlying liver regeneration by $\mathrm{hPH}$ after $\mathrm{PHx}$.

\section{MATERIALS AND METHODS}

hPH Preparation hPH (Laennec, Green Cross WellBeing Corp., Seongnam, Korea) was prepared by the hydrolysis of human placenta using $\mathrm{HCl}$ and pepsin.

Radical Scavenging Activity and Lipid Peroxidation Inhibitory Effect of hPH 1,1-Diphenyl-2-picrylhydrazyl (DPPH) radical scavenging activity was measured as follows; $10 \mu \mathrm{L}$ of diluted $\mathrm{hPH}$, dissolved in distilled water (DW), was prepared in a 96 well plate, and then $190 \mathrm{~mL}$ of $200 \mathrm{mM}$ DPPH, dissolved in methanol, was added. The mixture was incubated at room temperature for $30 \mathrm{~min}$ and the absorbance of the reaction mixture was measured at $517 \mathrm{~nm}$. DPPH radical scavenging activity (\%) was expressed as follows:

$$
\begin{aligned}
& \% \text { scavenging } \\
& =\frac{\text { control absorbance }- \text { sample absorbance }}{\text { control absorbance }} \times 100
\end{aligned}
$$

Malondialdehyde (MDA) was measured as a marker of lipid peroxidation. The brains of male Sprague-Dawley (SD) rats were dissected and homogenized in phosphate buffered saline at a ratio of $1: 10(\mathrm{w} / \mathrm{v})$. The homogenate was centrifuged at $1600 \times \boldsymbol{g}$ for $20 \mathrm{~min}$ at $4^{\circ} \mathrm{C}$. Five hundred microliters of the supernatant was then taken and incubated with $0.3 \mathrm{~mL}$ of $\mathrm{hPH}$ at different concentrations, $0.1 \mathrm{~mL}$ of $50 \mu \mathrm{M} \mathrm{FeCl}$, and $0.1 \mathrm{~mL}$ of $0.1 \mathrm{mM}$ ascorbic acid at $37^{\circ} \mathrm{C}$ for $30 \mathrm{~min}$. The color of the MDA-thiobarbituric acid (TBA) complex was detected at $532 \mathrm{~nm}$. The percent inhibition was calculated using the following formula:

$$
\begin{aligned}
& \text { \%Inhibition } \\
& =\frac{\text { control absorbance }- \text { sample absorbance }}{\text { control absorbance }} \times 100
\end{aligned}
$$

\section{HepG2 Cell and Human Primary Hepatocyte Prolifera-} tion HepG2 hepatocarcinoma cells were purchased from the American Type Culture Collection (ATCC, Manassas, VA, U.S.A.), and human primary hepatic cells were purchased from Biopredic International (\#HEP1870, Paris, France). The HepG2 cells were maintained as a monolayer in RPMI medium supplemented with $10 \%$ fetal bovine serum (FBS) and $1 \%$ penicillin $(100 \mathrm{U} / \mathrm{mL})-$ streptomycin $(100 \mu \mathrm{g} / \mathrm{mL})$ in humidified $5 \% \quad \mathrm{CO}_{2}$ atmosphere at $37^{\circ} \mathrm{C}$. Hepatocytes were maintained as a monolayer, and the medium and culture method were in accordance with the protocol provided by the manufacturer. Cell proliferation was measured by the 3-(4,5-dimethylthiazol2-yl)-2,5-diphenyltetrazolium bromide (MTT) reduction method. HepG2 were synchronized by serum starvation for $24 \mathrm{~h}$. The 10\% FBS and serially diluted hPH samples were added to the medium at a ratio of $1: 9$ and cultured for $24 \mathrm{~h}$. After incubation, 5\% MTT solution was added and cultured at $37^{\circ} \mathrm{C}$ for $2 \mathrm{~h}$. The absorbance was measured at $540 \mathrm{~nm}$ using a spectrophotometer (Molecular devices plus 384, U.K.). Cell proliferation of human primary hepatocytes was also analyzed by the MTT assay using the same procedure used to analyze the HepG2 cells; however, serum starvation was not performed for hepatocytes. After starvation for $18 \mathrm{~h}$, HepG2 cells were treated with various concentrations of IL-6 (12.5, 25, 50, and $10 \mathrm{ng} / \mathrm{mL}$ ) with or without $1 \mu \mathrm{g} / \mathrm{mL}$ LMT-28 (Sigma-Aldrich, Cat. No.; SML1628) and incubated for $48 \mathrm{~h}$. In addition, after starvation for $18 \mathrm{~h}$, the cells were treated with various concentrations of $\mathrm{hPH}\left(3^{4}, 3^{6}\right.$, and $\left.3^{8}\right)$ with or without $1 \mu \mathrm{g} / \mathrm{mL}$ LMT-28 and incubated for $48 \mathrm{~h}$. The proliferation of HepG2 cells was analyzed by the MTT assay as described above.

Analysis of Cytokines and Growth Factors in Supernatant of Human Primary Hepatocyte The concentrations of IL-6 in hepatocyte supernatants were analyzed. The $3^{6}$ dilution was selected as the concentration of hPH as it showed the highest efficacy identified in the cell proliferation test. Samples were obtained at $1,2,4,8,12$, and $24 \mathrm{~h}$ after treatment with the diluted hPH and analyzed with the Luminex 200 System (Luminex, Austin, TX, U.S.A.).

Western Blot Analysis Extracellular signal-regulated kinase (ERK) and signal transducer and activator of transcription 3 (STAT3) were measured by phosphorylation status using hepatocyte lysates. Western blot analysis was performed according to standard procedures using antibodies specific for Erk1/, phospho-Erk1/2; Thr202/Tyr204, phospho-STAT3, and phospho-STAT3; Tyr705. All antibodies were purchased from Cell Signaling Technology Inc. (Danvers, MA, U.S.A.) Images were captured and band intensity was quantified by densitometry using the Image J 1.41 software (NIH, Bethesda, MD, U.S.A.).

Liver Regeneration Effect of hPH in Rats after Partial Hepatectomy A total of 90 healthy male SD-rats, weighing $280-330 \mathrm{~g}$ each, were randomly divided into six groups. Each group was sub-divided into three groups, 1-d, 3-d, and 5 -d according to the autopsy schedule (Table 1). hPH was administered at 1.8 or $3.6 \mathrm{mg} / \mathrm{kg}$ body weight once daily subcutaneously before the autopsy, including $2 \mathrm{~d}$ before surgery, and was administered $30 \mathrm{~min}$ before the PHx. Losartan, as a 
positive control drug, was orally administered at $5 \mathrm{mg} / \mathrm{kg}$ body weight for $30 \mathrm{~min}$ before $\mathrm{PHx}$ and was administered once daily until autopsy. Median lobes and left lobes, accounting for about $70 \%$ of the size of the liver of each SD rat, were excised. Hepatic resection was performed according to the Higgins and Anderson method. ${ }^{28)}$ The excised liver tissue was weighed and used for the liver regeneration rate analysis. All the experimental procedures were checked and approved by the Institutional Animal Care and Use Committee (IACUC) of the Hoseo University (Approval No.: HTRC-16-96(1))

Liver Regeneration Ratio/Serum Analysis Liver regeneration rates were calculated using resected liver weight and autopsy liver weight. The total liver weight was calculated as $70 \%$ of the median and left lobes. The liver weights were measured at days 1, 3, and 5 after PHx. However, the liver regeneration rate of the sham group was expressed as the ratio of the sum of the weights of the right and caudate lobes to the total liver weight measured at sacrifice.

$$
\begin{aligned}
& \text { Liver regeneration rate } \\
& \qquad=\frac{\text { liver weight at sacrifice }}{\text { resected liver weight } \times(100 / 70)} \times 100
\end{aligned}
$$

The blood samples collected from the rats into serum separator tubes were centrifuged at $3000 \mathrm{rpm}$ for $15 \mathrm{~min}$. Serum levels of AST, ALT and alkaline phosphatase (ALP) were measured with a Hitachi 7020 automated biochemistry analyzer (HITACHI Co., Ltd., Tokyo, Japan).

Histological Analysis Liver were fixed in 10\% neutral buffered formalin, embedded in paraffin, cut into $4-\mu \mathrm{m} \mathrm{sec}$ tions, and stained with hematoxylin and eosin (H\&E). Double

Table 1. The Composition of Experimental Group and the Number of

\begin{tabular}{|c|c|c|c|c|c|}
\hline \multirow{2}{*}{ Group } & \multirow{2}{*}{ Treatment } & \multicolumn{4}{|c|}{ Animal number of autopsy } \\
\hline & & $1 \mathrm{~d}$ & $3 d$ & $5 \mathrm{~d}$ & Total \\
\hline Sham control & Vehicle & 6 & 6 & 6 & 18 \\
\hline PHx + Vehicle & $\mathrm{PHx}^{a}+$ vehicle & 6 & 6 & 6 & 18 \\
\hline $\mathrm{PHx}+1 \mathrm{X}$ Vehicle & $\mathrm{hPH}^{b)} 1.8 \mathrm{~mL} / \mathrm{kg}$ & 6 & 6 & 6 & 18 \\
\hline PHx $+2 \mathrm{X}$ Vehicle & $\mathrm{hPH}^{b)} 3.6 \mathrm{~mL} / \mathrm{kg}$ & 6 & 6 & 6 & 18 \\
\hline PHx + Losartan & Losartan $5.0 \mathrm{mg} / \mathrm{kg}$ & 6 & 6 & 6 & 18 \\
\hline
\end{tabular}
Animals Used

a) PHx: 2/3 Partial hepatectomy, b) hPH: human placenta hydrolysate. nuclei and mitotic cells were counted by observing H\&E stained slides. Approximately 1000 liver cells were observed under an optical microscope, and the results were expressed in rate per thousand (\%o). In). In addition, immunohistochemistry (IHC) staining was performed to identify proliferating cell nuclear antigen (PCNA), $K_{\mathrm{i}}-67$, and F4/80 positive cells using commercial kits), and the results were expressed as the percentage $(\%)$ of positive cells in the total cell count or positive cell count per $400 \times$ field after observing more than 10 fields. The IHC kit (Cat no.: ab80436) and antibodies (Cat no.: PCNA; ab29, $K_{\mathrm{i}}-67$; ab15580, F4/80; ab100790) were purchased from Abcam plc. (Cambridge, U.K.).

Assay of HGF, IL-6, and TNF- $\alpha$ in Liver Homogenate Ten milliliters of phosphate buffered saline was added per $1 \mathrm{~g}$ of liver tissue cut into $1-2 \mathrm{~mm}$, and the tissues were homogenized. The homogenate was centrifuged at $5000 \times \boldsymbol{g}$ for $10 \mathrm{~min}$ and the supernatant was collected and used for the assay. Supernatants were used for IL- 6 , TNF- $\alpha$, and HGF assays using a commercial assay kit (MyBioSource, San Diego, CA, U.S.A.).

Statistical Analysis Data were expressed as mean \pm standard deviation (S.D.). Statistical differences between means were determined using one-way ANOVA followed by a post hoc test (Tukey). Differences between groups were rated significant at a probability error $(p)$ of $>0.05$.

\section{RESULTS}

Antioxidant Capacity of Human Placenta Hydrolysate It was confirmed that hPH promoted the scavenging activity of DPPH radical (Fig. 1A) and inhibited MDA induced by $\mathrm{FeCl}_{3}$ in the brain homogenate (Fig. 1B) in a dose-dependent manner.

Effect of Human Placenta Hydrolysate on Hepatocyte Proliferation To confirm the hepatocyte proliferation effect of hPH, serially diluted hPH was treated with HepG2 and hepatocytes. hPH showed significant HepG2 cell proliferation effect at $24 \mathrm{~h}$ (Fig. 2A) and $48 \mathrm{~h}$ (Fig. 2B) after treatment. Especially, in the $3^{3}$-fold diluted $\mathrm{hPH}$-treated group, the cell proliferation rate was increased by $21 \%$ after $24 \mathrm{~h}$ of treatment compared with the untreated group, indicating the highest cell growth promotion effect. In addition, hPH showed significant hepatocyte proliferation effect at $24 \mathrm{~h}$ after treatment. In hepatocytes, the highest proliferation rate was observed in the
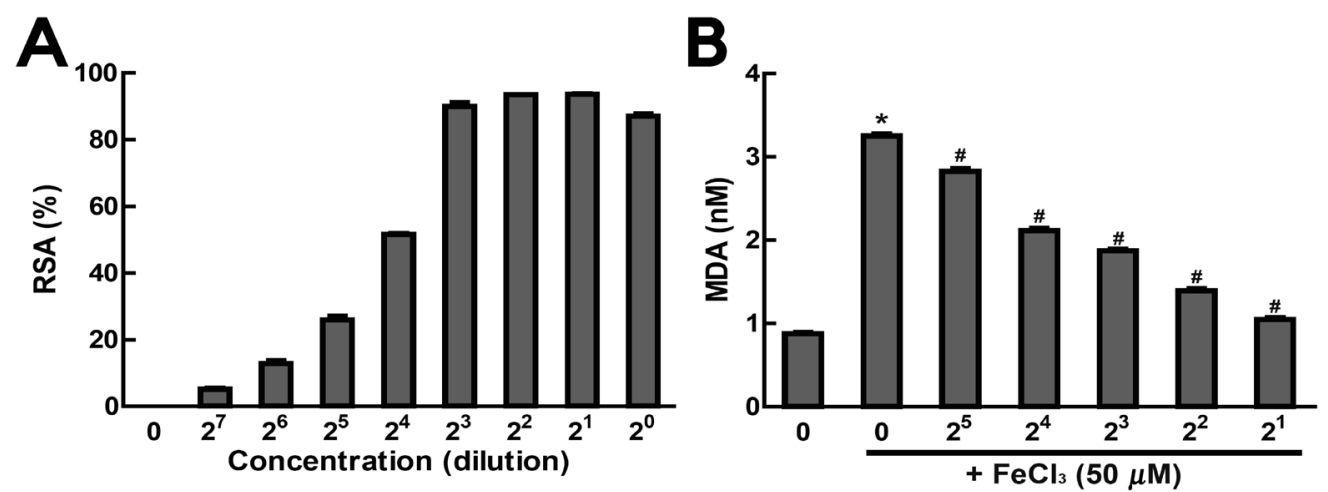

Fig. 1. Composition and Antioxidant Effect of Human Placenta Hydrolysate

DPPH radical scavenging activity (RSA) and MDA inhibitory activity were measured. DPPH-RSA was measured using $200 \mathrm{mM}$ DPPH and diluted hPH (A). Malondialdehyde (MDA) was measured by adding $\mathrm{FeCl}_{3}$ and ascorbic acid to the brain homogenate of rats and adding diluted hPH (B). All results are expressed as means $\pm \mathrm{S} . \mathrm{D}$. $(n=\mathrm{A}: 2 \text {, B and C: } 3)^{*} p<0.05$ compared with non-treat group. ${ }^{\#} p<0.05$ compared with $\mathrm{FeCl}_{3}$ treat group. 


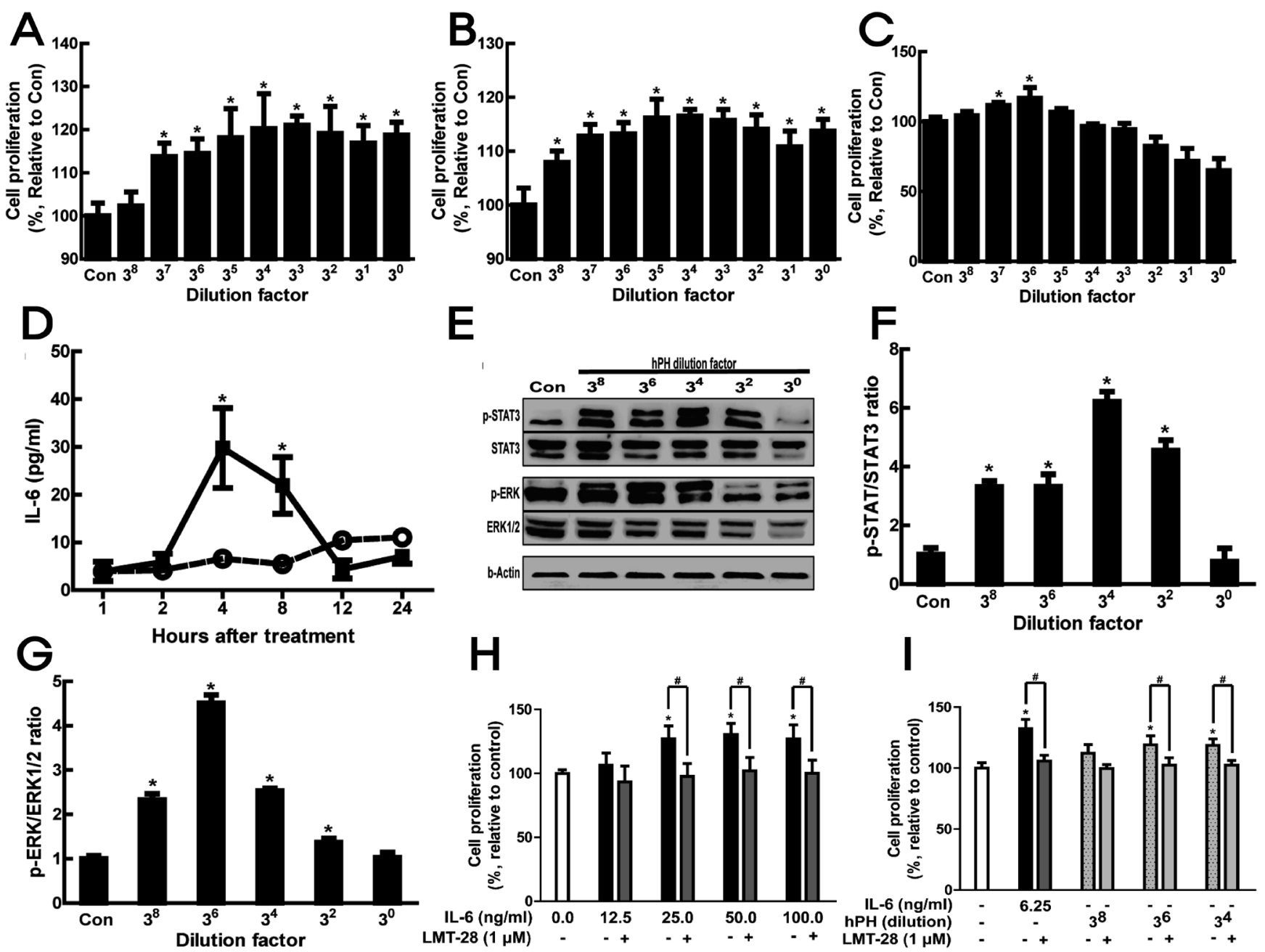

Fig. 2. Cell Proliferation Effect of Human Placenta Hydrolysate

Cell proliferation effect of human placenta hydrolysate was measured with HepG2 ( $24 \mathrm{~h}: \mathrm{A}, 48 \mathrm{~h}: \mathrm{B})$ and human primary hepatocytes $(24 \mathrm{~h}: \mathrm{C})$ by MTT assay ( $n=4)$. Changes in IL-6 (D) concentrations after $3^{6}$-fold diluted human placenta hydrolysate treatment in hepatocyte $(n=4)$. Representative Western blot images (E) show that $p$ STAT3 and $p$-ERK were significantly increased in $3^{2}-3^{8}$-fold diluted human placenta hydrolysate treated group $(\mathrm{F}, \mathrm{G}),(n=3)$. Human primary hepatocytes were incubated with various concentrations of IL-6 with or without LMT-28 (H) for $48 \mathrm{~h}$ and various concentrations of hPH with or without LMT-28 (I) $(n=4)$. Results are expressed as means \pm S.D. $* p<0.05$ compared with Con group or Vehicle group. ${ }^{*} p<0.05$ compared LTM-28 treat with non-treat.

$3^{6}$-fold diluted hPH sample (Fig. 2C). The changes in IL-6 levels in human primary hepatocytes treated with hPH were investigated by concentration- and time-dependent methods. Changes in IL-6 expression were investigated according to changes in $\mathrm{hPH}$ concentration and also based on time, 4 and $24 \mathrm{~h}$. The $3^{6}$-fold diluted $\mathrm{hPH}$ was used as a representative concentration, and IL- 6 concentration was investigated at 1 , $2,4,8,12$, and $24 \mathrm{~h}$ after $\mathrm{hPH}$ treatment. It was found that the concentration of IL- 6 began to increase considerably from $4 \mathrm{~h}$ after hPH treatment and continued to rise until $8 \mathrm{~h}$ (Fig. 2D). STAT3 and ERK, known to regulate the expression of regeneration genes, are regulated by IL-6 and HGF. The activity of these signaling molecules was enhanced by $\mathrm{hPH}$ treatment (Figs. 2E-G). IL-6 and hPH were co-treated with LMT-28, an antagonist of IL-6, to determine whether the cell proliferation effect of hPH was due to IL-6. In human primary hepatocytes, IL-6 demonstrated the maximum growth promotion effect at $25 \mathrm{ng} / \mathrm{mL}$ compared with Con (Fig. $2 \mathrm{H}$ ). Up to $19 \%$ cell growth promotion was observed at $3^{6}$-fold diluted $\mathrm{hPH}$ when human primary hepatocytes were treated with various concentrations of $\mathrm{hPH}$, and the cell growth promotion effect of $\mathrm{hPH}$ was completely inhibited by LMT-28 (Fig. 2I).
Effect of Human Placenta Hydrolysate on Liver Regeneration in Rats after Partial Hepatectomy To confirm the liver regeneration effect of $\mathrm{hPH}$, two doses of $\mathrm{hPH}(1 \mathrm{x}$ or $2 \mathrm{x}$, subcutaneously (s.c.)) and losartan (5 mg/kg, per os (p.o.)), an angiotensin II receptor antagonist used as a positive drug, were administered to SD rats after PHx. Regeneration rate was assessed by measuring liver weights at days 1,3 , and 5 after $\mathrm{PHx}$. In the hepatectomized rat, the regeneration ratio was significantly higher in the $2 \mathrm{x} \mathrm{hPH}$ treatment groups than in the vehicle treatment group at days 1 and 3. On day 5, there was no significant difference among the treated groups. In the sham group, the regeneration ratio did not change with time (Fig. 3A). The levels of HGF, IL-6, and TNF- $\alpha$ were significantly higher in the $1 \mathrm{x}$ and $2 \mathrm{x}$ hPH treatment groups than in the vehicle treatment group on day 1. Levels of TNF- $\alpha$ and IL-6 were significantly higher in the hPH treatment group than in the vehicle treatment group at day 3. The levels of all the factors were significantly higher in the losartan treatment group than in the vehicle treatment group at day 1 but decreased rapidly after this day (Figs. 3B-D). To evaluate the effect of $\mathrm{hPH}$ on the activation of Kupffer cells in the partial hepatectomized rats, F4/80 was assessed by IHC staining. The 
A

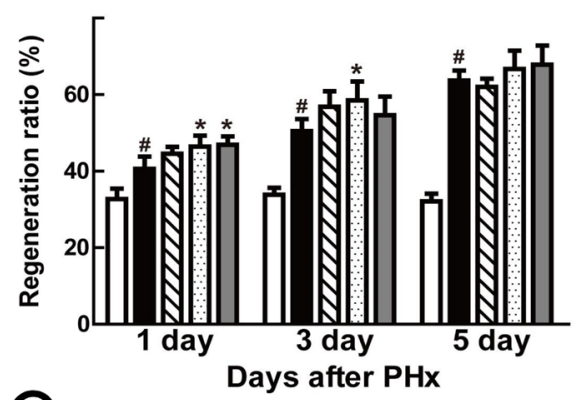

C

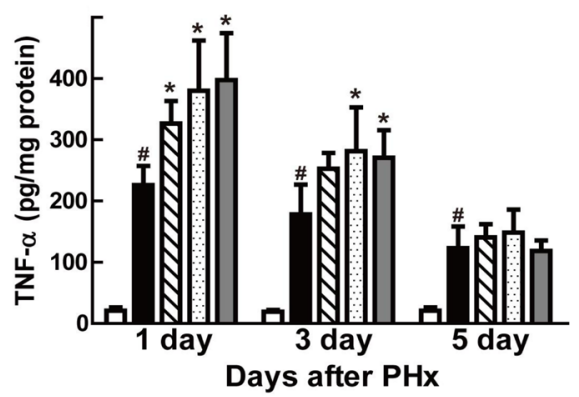

E

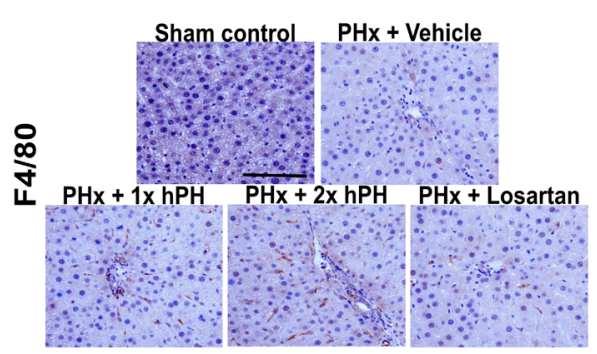

B

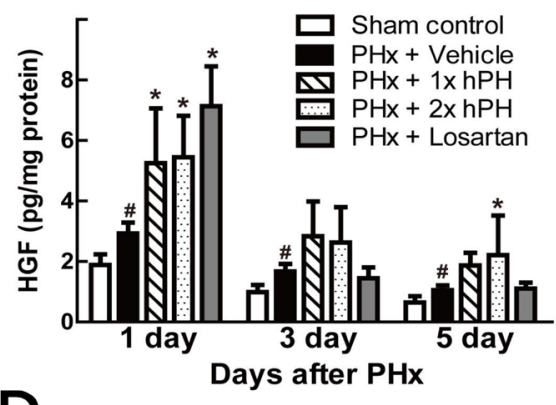

D

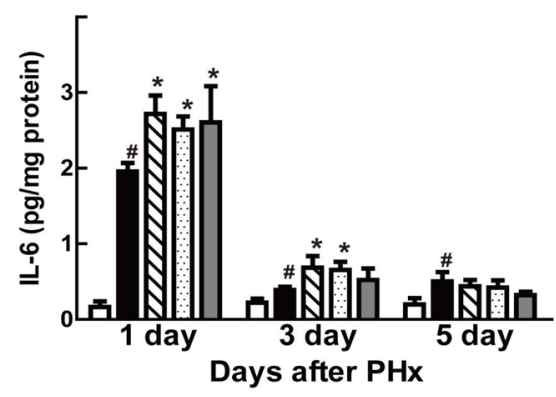

F

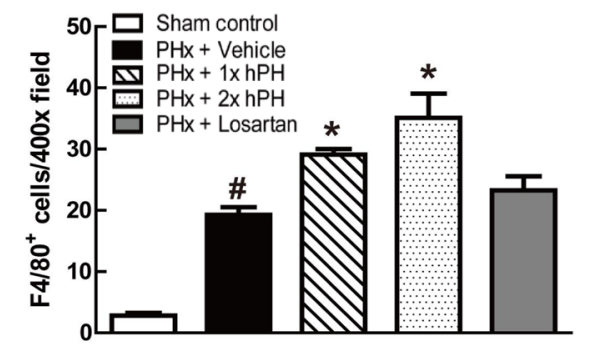

Fig. 3. Effects of Human Placenta Hydrolysate on Liver Regeneration in Rats after Partial Hepatectomy

The liver regeneration rate was calculated as weight ratio at 1,3, and $5 \mathrm{~d}$ after partial hepatectomy (A), HGF (B), TNF- $\alpha$ (C) and IL-6 (D) were analyzed in hepatic homogenate supernatant. Activation of kupffer cells was confirmed by F4/80 IHC staining (E) and positive cell counted (F), $(n=6)$. Results are expressed as means \pm S.D., ${ }^{\#} p<0.05$ compared with sham control group, ${ }^{*} p<0.05$ compared with $\mathrm{PHx}+$ vehicle group. (Color figure can be accessed in the online version.)

number of F4/80-positive cells increased on day 1 after PHx in the $\mathrm{hPH}$ treatment groups but not in the losartan treatment groups, and the peak value was significantly higher in the $2 \mathrm{x} \mathrm{hPH}$ treatment group than in the vehicle treatment group (Figs. 3E, F).

Histological Change by Human Placenta Hydrolysate in Rats after Partial Hepatectomy For the double nuclear cell ratio, the ratio in the $2 \mathrm{x} h \mathrm{hH}$ treatment group was significantly increased at days 1,3 , and 5 compared with that in the vehicle treatment group. For the mitosis cell ratio, the ratio in the $2 \mathrm{x}$ hPH treatment group was significantly increased compared with that in the vehicle treatment group at days 3 and 5. In the losartan group, the ratio significantly increased at day 1 or/and 3 but decreased rapidly after these days (Figs. 4A-E, P, Q, 1- and 5-d photographs not shown). The ratio of PCNApositive cells increased to a peak of $64.2 \%$ at day 3 after PHx in all hPH and losartan treatment groups, and the peak value was significantly higher in the $2 \mathrm{x}$ hPH treatment group than in the vehicle treatment group (Figs. 4F-J, R, 1- and 5-d). Similarly, the number of $K_{\mathrm{i}}$-67-positive cells was also significantly higher in the $2 \mathrm{x} \mathrm{hPH}$ treatment group than in the vehicle treatment group. The number of $K_{\mathrm{i}}$-67-positive cells was also significantly higher in the $2 \mathrm{x} h \mathrm{hH}$ treatment group than in the vehicle treatment group at day 5, and the number in the losartan group was significantly higher than that in the vehicle treatment group at day 1 , but decreased rapidly after this day (Figs. 4K-O, S, 1- and 5-d). Moreover, it was confirmed that hPH significantly reduced serum AST, ALT, and ALP levels in the $2 \mathrm{x} \mathrm{hPH}$ treatment group compared with the vehicle treatment group (Figs. 4T-V).

Antioxidant Effect of Human Placenta Hydrolysate in Rats after Partial Hepatectomy To evaluate the effect of $\mathrm{hPH}$ on the antioxidant effect in the partial hepatectomized rats, thiobarbituric acid reactive substances (TBARs), glutathione (GSH), superoxide dismutase (SOD), and glutathione peroxidase (GPx) were analyzed using commercial assay kits. TBARS, as a marker of oxidative damage, showed a significant decrease in the hPH-treated group compared with that in the vehicle group (Fig. 5A). GSH, as a source of antioxidant enzymes, showed a significant increase in the hPH-treated group compared with that in the vehicle treatment group (Fig. 5B). Analysis of the activity of SOD and GPx, which are representative antioxidant enzymes, confirmed that the oxidative stress induced by partial hepatectomy was fully recovered by hPH administration (Figs. 5C, D). 

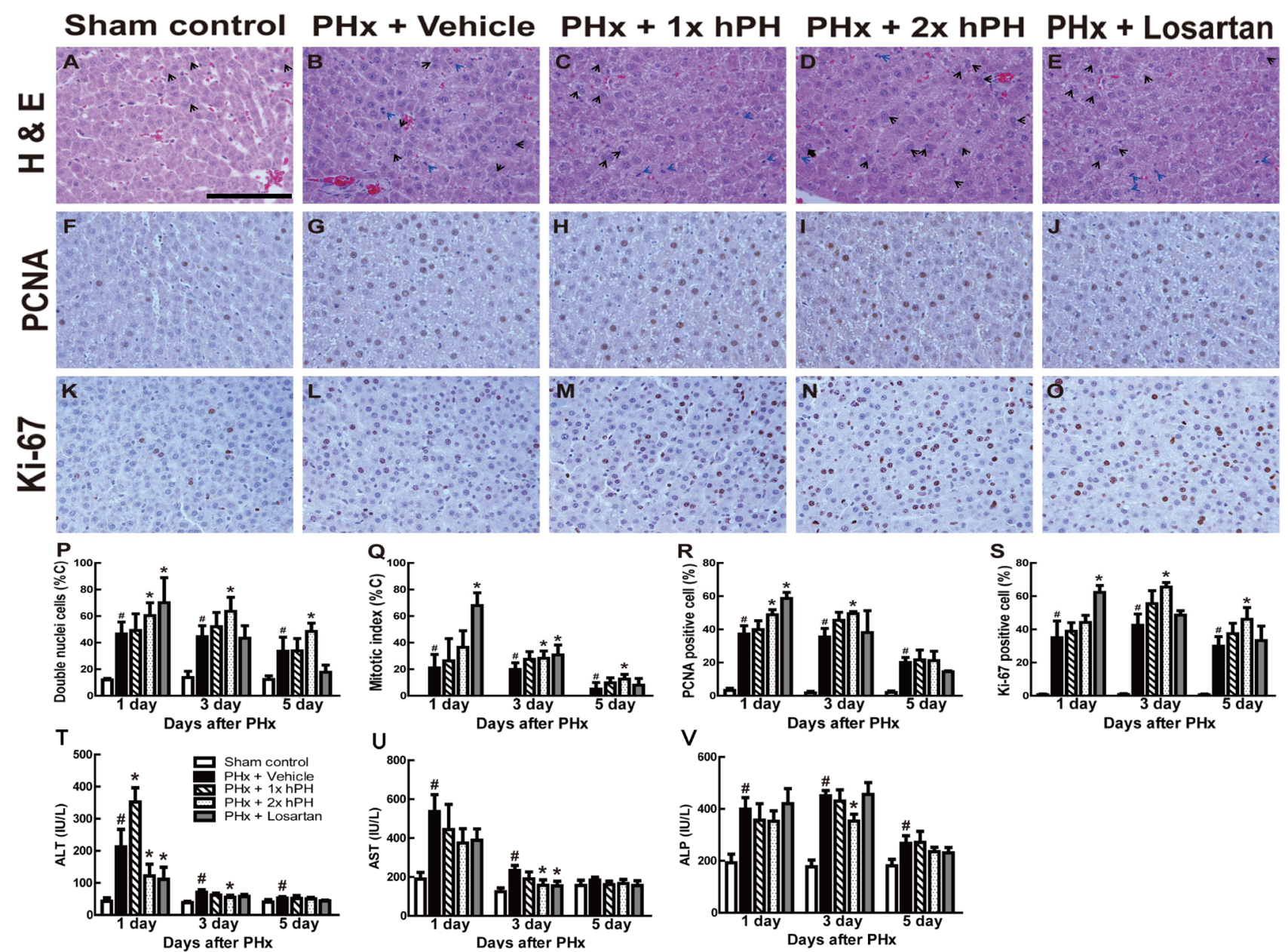

Fig. 4. Histological Evaluation in Rats after Partial Hepatectomy

Liver regeneration effect of human placenta hydrolysate was confirmed by histological evaluation. The proportion of mitosis and double neuclei cells was counted by the H\&E stain Double neuclei cells and mitosis were presented as blue arrow and black arrow respectively (A-E and P, Q). Also immunohistochemistry for PCNA (F-J and R) and $K_{\mathrm{i}}-67$ (K-O and S), the proportion of positive cells (brown to black) was counted. Each cells were counted under light microscope $(\times 400)$. The presented photographs are on day 3 after partial hepatectomy and the photographs on day 1 and 5 are not shown. Effect of human placenta hydrolysate on serum AST, ALT and ALP levels after partial hepatectomy $(\mathrm{T}-\mathrm{V})$. Results are expressed as means \pm S.D., ${ }^{*} p<0.05$ compared with sham control group, ${ }^{*} p<0.05$ compared with PHx + vehicle group. (Color figure can be accessed in the online version.)

\section{DISCUSSION}

The liver has a remarkable ability to regenerate after PHx, acute and chronic liver injury, or ischemic damage. Indeed the normal liver in rat is restored within about a week after PHx. During the rapid regeneration process, massive oxidative stress can occur, which can slow down the regeneration process, ${ }^{25)}$ and thus, proper removal of oxidative stress may be facilitate liver regeneration.

Several bioactive molecules in hPH have been spotlighted in Western and Oriental medicine. ${ }^{26,27)}$ There are abundant biologically important factors in $\mathrm{hPH}$, and some of these cytokines and growth factors are known to be essential for liver regeneration. ${ }^{28-31)}$ In primary hepatic cells, we confirmed that IL-6 was induced by treatment with hPH. It was also confirmed that LMT-28, an IL-6 antagonist, inhibited the cell growth promoting effect in HepG2 cells. IL-6 is an important priming factor, which promotes G0 to G1 transition of hepatocytes and allows effective response to growth factors. ${ }^{32)}$ Moreover, it activates approximately $40 \%$ of the early genes involved in liver regeneration, including STAT3 and ERK. ${ }^{32)}$ It is known that STAT3 promotes cell-cycle progression and cell proliferation under physiological growth conditions. ${ }^{33)}$ Furthermore, ERK induces cell proliferation and cyclin D1 expression, ${ }^{33-37)}$ which is an important checkpoint protein in hepatic cell growth. Indeed, in this study, it was confirmed that STAT3 and ERK were activated by treatment of hPH in primary hepatic cells. In primary hepatic cells, treatment with high concentrations of $\mathrm{hPH}\left(>3^{5}\right)$ leads to hepatic toxicity. However, serum levels of ALT, AST, and ALP were significantly reduced in the $2 \mathrm{xhPH}$ treatment group compared with the levels in the vehicle treatment group, consistent with the previous reports. ${ }^{38)}$ Therefore, the cytotoxicity observed in the in vitro results does not undermine the safety in vivo.

Cell division is rarely observed in normal hepatocytes, as most hepatic cells are in the G0 phase of the cell cycle. ${ }^{2)}$ However, in the case of large damage such as partial hepatectomy, most hepatocytes rapidly re-enter the cell cycle. In the case of rats, the DNA synthesis is increased by entering the $\mathrm{S}$ phase in the cell cycle from $12 \mathrm{~h}$, and peak at about $24 \mathrm{~h}{ }^{20)}$ Thereafter, mitosis occurs and double nuclear cells increase, eventually occurs liver regeneration. ${ }^{2)}$ We investigated whether $\mathrm{hPH}$ administration could promote liver regeneration after PHx in vivo. The concentrations of IL-6, TNF- $\alpha$, and 
A

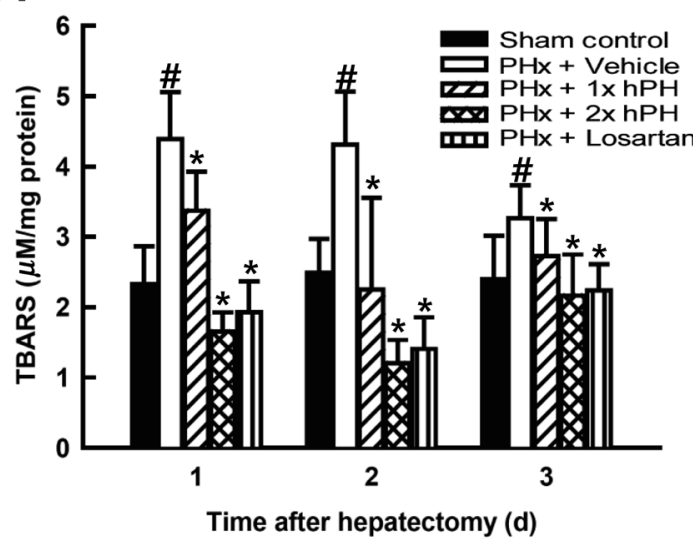

C

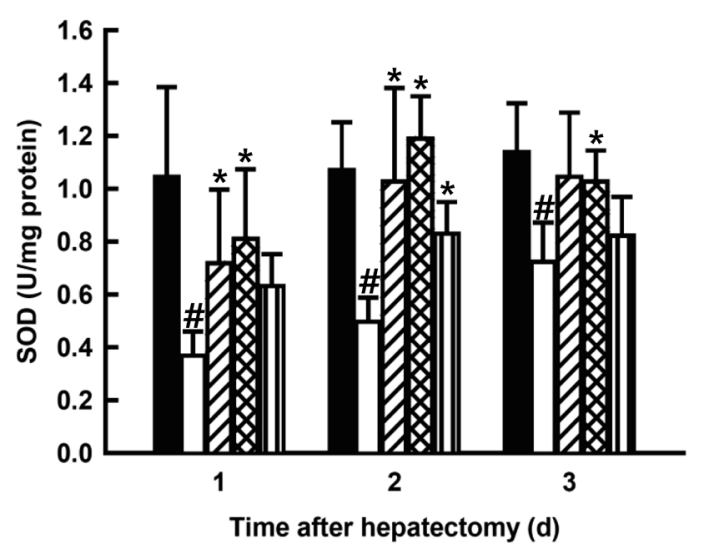

B

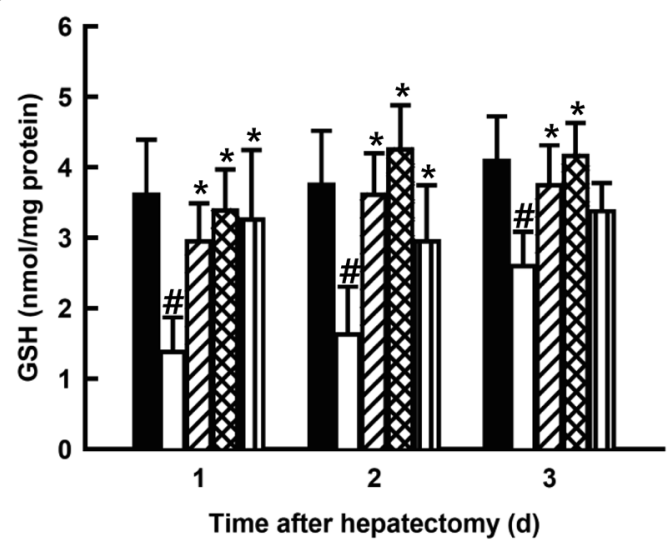

D

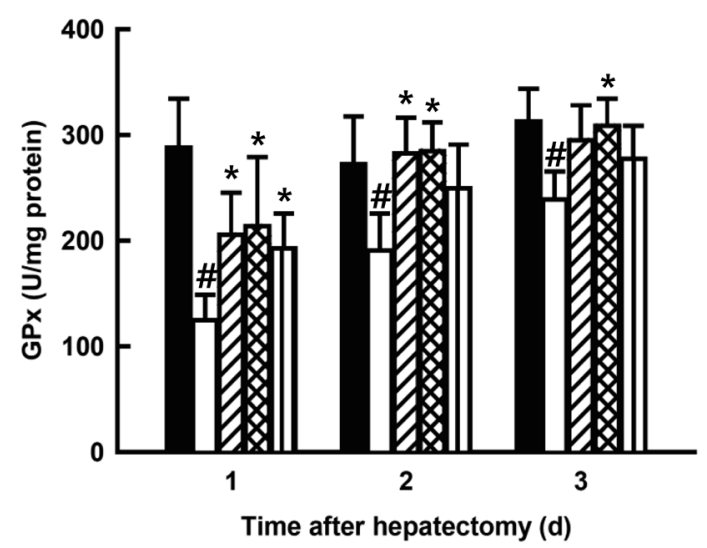

Fig. 5. Effects of Human Placenta Hydrolysate on Oxidative Stress in Rats after Partial Hepatectomy

TBARS (A), GSH (B), SOD (C) and GPx (D) were analyzed in hepatic homogenate supernatant as a marker of oxidative stress at 1, 3, and $5 \mathrm{~d}$ after partial hepatectomy using commercial ELISA kit. Results are expressed as means \pm S.D., ${ }^{\#} p<0.05$ compared with sham control, ${ }^{*} p<0.05$ compared with PHx + vehicle $(n=6)$.

HGF were dramatically induced in the $2 \mathrm{x} \mathrm{hPH}$ treatment group. These results are in agreement with those of previous reports, indicating that the up-regulation of IL-6, TNF- $\alpha$, and HGF enhances liver regeneration. ${ }^{2)}$ Activation of Kupffer cells was also confirmed by F4/80-IHC staining. These results are consistent with those of previous studies in which TNF- $\alpha$ and IL-6 were secreted from activated Kupffer cells. ${ }^{2)}$ In process of cell cycle conversion, HGF, TNF- $\alpha$ and IL- 6 have been implicated in regulating liver regeneration. According to the recent studies using a liver-knockout of Met have confirm that the HGF/Met pathway is major route for DNA synthesis after liver damage. Also HGF is inducer of DNA synthesis in in vitro. ${ }^{20)}$ IL-6 is a major component in hepatic physiology, including hepatoprotection, acute-phase response and mitogenesis. In particular, IL-6 plays an important role in liver regeneration with STAT3. ${ }^{32)}$ The absence of TNF- $\alpha$ does not damage liver, however TNF- $\alpha$ is also required for a cell proliferation after partial hepatectomy in TNF-receptor-1 knockout mice. Because TNF- $\alpha$ induces the production of IL-6 via upregulation of nuclear factor-kappaB $(\mathrm{NF}-\kappa \mathrm{B}) .{ }^{39)}$ Furthermore, we showed that cell mitosis and double nuclei ratio, which are markers of cell proliferation, ${ }^{40)}$ were increased in the $2 \mathrm{x}$ $\mathrm{hPH}$ treatment group. Regeneration of normal cells occurs through the differentiation of precursor cells. ${ }^{41)}$ However, in the liver, cell proliferation occurs by self-renewal of already mature cells. Therefore, mitosis and double nuclear cells can be observed in the liver being regenerated. ${ }^{41)}$ We confirmed that the percentage of PCNA and $K_{\mathrm{i}}-67$ positive hepatocytes, which are markers of DNA replication and proliferation activ$\mathrm{ity}^{42)}$ respectively, were significantly enhanced in $2 \mathrm{x} \mathrm{hPH}-$ treated livers $3 \mathrm{~d}$ after PHx. These results suggest that several cytokines and bioactive molecules contained in hPH triggered repair mechanisms via various signal pathways.

It has been found that lipid peroxidation occurs in the early phase of liver regeneration ${ }^{25,43)}$ and that diminished lipid peroxidation contributes to cell proliferation after $\mathrm{PHx}^{44)}$ In addition, it has been reported that a damaged oxidative stress defense system inhibits liver regeneration. ${ }^{45-47)}$ The crucial players for defending against oxidative stress include detoxifying electrophiles and radicals and antioxidant proteins and enzymes, such as SOD, GPx, and GSH. ${ }^{44)}$ Superoxide anion is dismutated by SOD to hydrogen peroxide $\left(\mathrm{H}_{2} \mathrm{O}_{2}\right)$, which is detoxified to water by GPx. ${ }^{48)}$ Importantly, GPx requires an adequate amount of GSH to detoxify $\mathrm{H}_{2} \mathrm{O}_{2}$; therefore, depletion of GSH below normal levels can lead to, or favor, mitochondrial dysfunction and cell death. ${ }^{49)}$ This study has shown that the levels of TBARS were significantly increased in the liver at days 1, 3, and 5 after PHx. In addition, PHx also damaged antioxidant systems such as SOD, GPx, and GSH. These damages were mostly prevented by $1 \mathrm{x}$ or $2 \mathrm{x} \mathrm{hPH}$ treatments. 
It has been reported that the major anti-oxidant components in human placenta extract are uracil, tyrosine, phenylalanine, and tryptophan. Approximately 59\% of the antioxidative effects of human placenta extract can be explained by the actions of these components. ${ }^{11)}$ In previous studies that used the same $\mathrm{hPH}$, it was confirmed that $\mathrm{hPH}$ contains various amino acids, including arginine $(0.08 \%)$, lysine $(0.1 \%)$, phenylalanine $(0.08 \%)$, tyrosine $(0.03 \%)$, leucine $(0.12 \%)$, methionine $(0.03 \%)$, valine $(0.04 \%)$, alanine $(0.08 \%)$, serine $(0.07 \%)$, and threonine $(0.06 \%) .{ }^{50)}$ Therefore, it can be assumed that these amino acids have a role in removing oxidative stress and increasing antioxidant enzymes.

According to the previous study, nuclear factor-E2-related factor 2 (Nrf2) pathway-related gene expression in HepG2 cells was activated by $\mathrm{hPH}$ treatment. ${ }^{51)}$ The activation of Nrf2 upregulates antioxidant enzymes, including SOD and GPx, reducing ROS. ${ }^{52)}$ In many studies, Nrf2 was upregulated by arginine, ${ }^{53,54)}$ alanine,${ }^{53)}$ lysine,${ }^{53)}$ phenylalanine ${ }^{55)}$ and tyrosine $\mathrm{e}^{55,56)}$ as a major amino acid contained in $\mathrm{hPH}$. According to previously study, The Nrf2 signaling pathway is negatively regulated by Keap1. ${ }^{53)}$ There is a directly interacted between p62 and Keap1 and that the amino acids and the three arginine residues such as positions 380,415 , and 483 in Keap1 are essential for the interaction between these proteins. ${ }^{53)}$ Thus, Nrf2 seems to be one of major pathway for the antioxidant effect of amino acids. In addition, previous studies have shown that amino acids stimulate DNA synthesis in the normal liver of protein-deprived animals. ${ }^{56)}$ It has been shown that the infusion of amino acids increases the activity of certain enzymes involved in the synthesis of pyrimidine nucleotides and DNA during liver regeneration process. ${ }^{57)}$ Leucine, threonine, and valine, found to be contained in hPH, are more essential than other amino acids in inducing new DNA synthesis in protein-deficient animals. ${ }^{57)}$ In contrast to these results, some studies have shown that elimination of lipid peroxidation inhibits liver regeneration. ${ }^{58,59)}$ These results suggest that lipid peroxidation may paradoxically play a role in the cell proliferation cascade. Potent antioxidants such as vitamin E could induce early termination of cell proliferation event to suppress liver regeneration. ${ }^{59)}$ Although many studies aiming at efficacy have reported positive results for antioxidant effects, a more careful interpretation is needed because anti-oxidative effects are bi-faceted in the tissue regeneration process.

In this study, we confirmed that hPH contains diverse growth factors and cytokines that are associated with liver regeneration and demonstrate efficacy in liver regeneration. Therefore, we suggest that $\mathrm{hPH}$ can trigger liver regeneration via cytokine- and growth factor-mediated signaling pathways. It was also suggested that $\mathrm{hPH}$ can eliminate oxidative stress during liver regeneration. Nevertheless, hPH has not yet been fully studied because it is known to contain various components other than cytokines, growth factors, and amino acids. This implies that a study of the undefined physiological activity of hPH is required. Taken together, hPH may be a good alternative for the treatment of liver injury and for the regeneration of the liver after living donor liver transplantation.

Acknowledgments This work was supported by Green Cross WellBeing Corporation (Seongnam, Gyeonggi-do, Korea). The funders had no role in data collection and analysis, decision to publish, or preparation of the manuscript.
Conflict of Interest The authors declare no conflict of interest.

\section{REFERENCES}

1) Saxena R, Zucker SD, Crawford JM, Zakim D, Boyer T. Anatomy and physiology of the liver. Hepatology: A Textbook of Liver Disease., 4th edition. (Zakim DZ, Boyer TD eds.) Sounders, Philadelphia, pp. 3-30 (2003).

2) Taub R. Liver regeneration: from myth to mechanism. Nat. Rev. Mol. Cell Biol., 5, 836-847 (2004).

3) Forbes SJ, Newsome PN. Liver regeneration-mechanisms and models to clinical application. Nature Reviews Gastroenterology and Hepatology, 13, 473-485 (2016).

4) Fausto N, Campbell JS, Riehle KJ. Liver regeneration. Hepatology, 43 (Suppl. 1), S45-S53 (2006).

5) Michalopoulos GK, DeFrances MC. Liver regeneration. Science, 276, 60-66 (1997).

6) Shirabe K, Shimada M, Gion T, Hasegawa H, Takenaka K, Utsunomiya T, Sugimachi K. Postoperative liver failure after major hepatic resection for hepatocellular carcinoma in the modern era with special reference to remnant liver volume. J. Am. Coll. Surg., 188, 304-309 (1999)

7) Balzan S, Belghiti J, Farges O, Ogata S, Sauvanet A, Delefosse D, Durand F. The "50-50 criteria" on postoperative day 5: an accurate predictor of liver failure and death after hepatectomy. Ann. Surg., 242, 824-828, discussion, 828-829 (2005).

8) Jung J, Lee H-J, Lee JM, Na K-H, Hwang S-G, Kim GJ. Placenta extract promote liver regeneration in CCl4-injured liver rat model. Int. Immunopharmacol., 11, 976-984 (2011).

9) Jung J, Moon JW, Choi J-H, Lee YW, Park S-H, Kim GJ. Epigenetic alterations of IL-6/STAT3 signaling by placental stem cells promote hepatic regeneration in a rat model with CC14-induced liver injury. International Journal of Stem Cells, 8, 79-89 (2015).

10) Koob TJ, Lim JJ, Massee M, Zabek N, Rennert R, Gurtner G, Li WW. Angiogenic properties of dehydrated human amnion/chorion allografts: therapeutic potential for soft tissue repair and regeneration. Vascular Cell, 6, 10 (2014).

11) Rameshbabu AP, Ghosh P, Subramani E, Bankoti K, Kapat K, Datta S, Maity PP, Subramanian B, Roy S, Chaudhury K, Dhara S. Investigating the potential of human placenta-derived extracellular matrix sponges coupled with amniotic membrane-derived stem cells for osteochondral tissue engineering. Journal of Materials Chemistry $B, 4,613-625$ (2016).

12) Shimokobe H, Sumida Y, Tanaka S, Mori K, Kitamura Y, Fukumoto K, Kakutani A, Ohno T, Kanemasa K, Imai S, Hibino S, Yoshikawa T. Human placental extract treatment for non-alcoholic steatohepatitis non-responsive to lifestyle intervention: A pilot study. Hepatol. Res., 45, 1034-1040 (2015).

13) Park SB, Kim K-N, Sung E, Lee SY, Shin HC. Human placental extract as a subcutaneous injection is effective in chronic fatigue syndrome: a multi-center, double-blind, randomized, placebo-controlled study. Biol. Pharm. Bull., 39, 674-679 (2016).

14) Choi JY, Lee K, Lee SM, Yoo SH, Hwang SG, Choi JY, Lee SW, Hwang JS, Kim KK, Kang HC, Cheon GJ, Park YM. Efficacy and safety of human placental extract for alcoholic and nonalcoholic steatohepatitis: an open-label, randomized, comparative study. Biol. Pharm. Bull., 37, 1853-1859 (2014).

15) Bose PD, Das BC, Hazam RK, Kumar A, Medhi S, Kar P. Evidence of extrahepatic replication of hepatitis E virus in human placenta. $J$. Gen. Virol., 95, 1266-1271 (2014).

16) Chatterjee P, Chiasson VL, Pinzur L, Raveh S, Abraham E, Jones KA, Bounds KR, Ofir R, Flaishon L, Chajut A, Mitchell BM. Human placenta-derived stromal cells decrease inflammation, placental injury and blood pressure in hypertensive pregnant mice. Clin. Sci., 130, 513-523 (2016). 
17) Kong M, Park SB. Effect of human placental extract on health status in elderly Koreans. Evid. Based Complement. Alternat. Med., 2012, 732915 (2012).

18) Taub R, Greenbaum LE, Peng Y. Transcriptional regulatory signals define cytokine-dependent and-independent pathways in liver regeneration. Seminars in liver disease. Vol. 19, Thieme Medical Publishers, Inc., New York, pp. 117-127 (1999).

19) Arias IM, Wolkoff AW, Boyer JL, Shafritz DA, Fausto N, Alter HJ, Cohen DE. The liver: biology and pathobiology. John Wiley \& Sons, NJ (2011).

20) Mao SA, Glorioso JM, Nyberg SL. Liver regeneration. Transl. Res., 163, 352-362 (2014).

21) Forman HJ, Torres M, Fukuto J. Redox signaling. Mol. Cell. Biochem., 234, 49-62 (2002).

22) Finkel T, Holbrook NJ. Oxidants, oxidative stress and the biology of ageing. Nature, 408, 239-247 (2000).

23) Barnouin K, Dubuisson ML, Child ES, Fernandez de Mattos S, Glassford J, Medema RH, Mann DJ, Lam EW-F. $\mathrm{H}_{2} \mathrm{O}_{2}$ induces a transient multi-phase cell cycle arrest in mouse fibroblasts through modulating cyclin D and $\mathrm{p} 21^{\mathrm{Cipl}}$ expression. J. Biol. Chem., 277, 13761-13770 (2002).

24) Mendelson KG, Contois L-R, Tevosian SG, Davis RJ, Paulson KE. Independent regulation of $\mathrm{JNK} / \mathrm{p} 38$ mitogen-activated protein kinases by metabolic oxidative stress in the liver. Proc. Natl. Acad. Sci. U.S.A., 93, 12908-12913 (1996).

25) Noguchi T, Mizumoto R. The significance of lipid peroxidation (free radical) on hepatocellular dysfunction following hepatectomy. Rinsho byori. The Japanese Journal of Clinical Pathology, 37, 994-998 (1989).

26) Guttmacher AE, Maddox YT, Spong CY. The human placenta project: placental structure, development, and function in real time. Placenta, 35, 303-304 (2014).

27) Salavati N, Sovio U, Mayo RP, Charnock-Jones DS, Smith G. The relationship between human placental morphometry and ultrasonic measurements of utero-placental blood flow and fetal growth. Placenta, 38, 41-48 (2016).

28) Galun E, Axelrod JH. The role of cytokines in liver failure and regeneration: potential new molecular therapies. Biochim. Biophys. Acta (BBA)-Mol. Cell Res., 1592, 345-358 (2002).

29) Gustot T. Beneficial role of G-CSF in Acute-on-Chronic Liver Failure: effects on liver regeneration, inflammation/immunoparalysis or both? Liver Int., 34, 484-486 (2014)

30) Goh YS, Henderson NC, Heredia JE, Red Eagle A, Odegaard JI, Lehwald N, Nguyen KD, Sheppard D, Mukundan L, Locksley RM. Eosinophils secrete IL-4 to facilitate liver regeneration. Proc. Natl. Acad. Sci. U.S.A., 110, 9914-9919 (2013).

31) Alegre ML. Select Effects of IL-13 in Driving Tissue Repair and Fibrosis. Am. J. Transplant., 16, 2771-2771 (2016).

32) Böhm F, Köhler UA, Speicher T, Werner S. Regulation of liver regeneration by growth factors and cytokines. EMBO Mol. Med., 2, 294-305 (2010).

33) Shih S-C, Ho T-C, Chen S-L, Tsao Y-P. Pigment epithelium-derived factor (PEDF) peptide promotes the expansion of hepatic stem/progenitor cells via ERK and STAT3-dependent signaling. American Journal of Translational Research, 9, 1114-1126 (2017).

34) Lai S-S, Zhao D-D, Cao P, Lu K, Luo O-Y, Chen W-B, Liu J, Jiang E-Z, Yu Z-H, Lee G, Li J, Yu DC, Xu XJ, Zhu MS, Gao X, Li CJ, Xue B. PP2Ac $\alpha$ positively regulates the termination of liver regeneration in mice through the AKT/GSK3 $\beta /$ Cyclin D1 pathway. $J$. Hepatol., 64, 352-360 (2016).

35) Goh YS, Henderson NC, Heredia JE, Eagle AR, Odegaard JI, Lehwald N, Chawla A. Eosinophils secrete IL-4 to facilitate liver regeneration. Proc. Natl. Acad. Sci. U.S.A., 110, 9914-9919 (2013).

36) Morgan JG, Dolganov GM, Robbins SE, Hinton LM, Lovett M. The selective isolation of novel cDNAs encoded by the regions surrounding the human interleukin 4 and 5 genes. Nucleic Acids Res.,
20, 5173-5179 (1992).

37) Minty A, Chalon P, Derocq JM, Dumont X, Guillemot JC, Kaghad M, Labit C, Leplatois P, Liauzun P, Miloux B, Minty C, Casellas P, Loison G, Lupker J, Shire D, Ferrara P, Caput D. Interleukin-13 is a new human lymphokine regulating inflammatory and immune responses. Nature, 362, 248-250 (1993).

38) Lei H, Cheng M, Li J, Zhou P, Luo X, Yu F. Components of human placental extract and its protective effect to rat from D-GalN induced acute liver injury. Zhonghua Yi Xue Za Zhi, 97, 1815-1819 (2017).

39) Fujiyoshi M, Ozaki M. Molecular mechanisms of liver regeneration and protection for treatment of liver dysfunction and diseases. $J$. Hepato-Biliary-Pancreatic Sci., 18, 13-22 (2011).

40) Assy N, Minuk G. Liver regeneration: methods for monitoring and their applications. J. Hepatol., 26, 945-952 (1997).

41) Fukuhara Y, Hirasawa A, Li X-K, Kawasaki M, Fujino M, Funeshima N, Katsuma S, Shiojima S, Yamada M, Okuyama T, Suzuki S, Tsujimoto $\mathrm{G}$. Gene expression profile in the regenerating rat liver after partial hepatectomy. J. Hepatol., 38, 784-792 (2003).

42) Muskhelishvili L, Latendresse JR, Kodell RL, Henderson EB. Evaluation of cell proliferation in rat tissues with BrdU, PCNA, Ki-67 (MIB-5) immunohistochemistry and in situ hybridization for histone mRNA. J. Histochem. Cytochem., 51, 1681-1688 (2003).

43) Ueda K, Yoshioka T, Takehara Y, Abe K. Lipoperoxides, vitamin E, and activities of superoxide dismutase, glutathione peroxidase, and catalase in regenerating rat liver. Biochem. Int., 7, 663-669 (1983).

44) Cheeseman KH, Collins M, Maddix S, Milia A, Proudfoot K, Slater T, Burton $\mathrm{G}$, Webb $\mathrm{A}$, Ingold $\mathrm{K}$. Lipid peroxidation in regenerating rat liver. FEBS Lett., 209, 191-196 (1986).

45) Yang S, Tan T, Wee A, Leow C. Mitochondrial respiratory function and antioxidant capacity in normal and cirrhotic livers following partial hepatectomy. Cellular and Molecular Life Sciences CMLS, 61, 220-229 (2004)

46) Gorla GR, Malhi H, Gupta S. Polyploidy associated with oxidative injury attenuates proliferative potential of cells. J. Cell Sci., 114, 2943-2951 (2001).

47) Dayoub R, Vogel A, Schuett J, Lupke M, Spieker SM, Kettern N, Hildt E, Melter M, Weiss TS. Nrf2 activates augmenter of liver regeneration (ALR) via antioxidant response element and links oxidative stress to liver regeneration. Mol. Med., 19, 237-244 (2013).

48) D’Autréaux B, Toledano MB. ROS as signalling molecules: mechanisms that generate specificity in ROS homeostasis. Nat. Rev. Mol. Cell Biol., 8, 813-824 (2007).

49) Fernandez-Checa JC, Kaplowitz N. Hepatic mitochondrial glutathione: transport and role in disease and toxicity. Toxicol. Appl. Pharmacol., 204, 263-273 (2005).

50) Kim J-K, Kim T-H, Park S-W, Kim H-Y, Kim SH, Lee SY, Lee S-M. Protective effects of human placenta extract on cartilage degradation in experimental osteoarthritis. Biol. Pharm. Bull., 33, 1004-1010 (2010)

51) Bak DH, Na J, Choi MJ, Lee BC, Oh CT, Kim JY, Han HJ, Kim MJ, Kim TH, Kim BJ. Anti-apoptotic effects of human placental hydrolysate against hepatocyte toxicity in vivo and in vitro. Int. J. Mol. Med., 42, 2569-2583 (2018).

52) Short J, Armstrong N, Zemel R, Lieberman I. A role for amino acids in the induction of deoxyribonucleic acid synthesis in liver. Biochem. Biophys. Res. Commun., 50, 430-437 (1973).

53) Lau A, Wang XJ, Zhao F, Villeneuve NF, Wu T, Jiang T, Sun Z, White E, Zhang DD. A noncanonical mechanism of Nrf2 activation by autophagy deficiency: direct interaction between Keap1 and p62. Mol. Cell. Biol., 30, 3275-3285 (2010).

54) Ramprasath T, Kumar PH, Puhari SSM, Murugan PS, Vasudevan V, Selvam GS. L-Arginine ameliorates cardiac left ventricular oxidative stress by upregulating eNOS and Nrf2 target genes in alloxaninduced hyperglycemic rats. Biochem. Biophys. Res. Commun., 428, 389-394 (2012). 
55) Kim DJ, Yoon SH, Ji SC, Yang JH, Kim YK, Lee SH, Yu K, Jang IJ, Chung JY, Cho JY. Ursodeoxycholic acid improves liver function via phenylalanine/tyrosine pathway and microbiome remodelling in patients with liver dysfunction. Scientific Reports, 8, 11874 (2018).

56) Kaspar JW, Jaiswal AK. Antioxidant-induced phosphorylation of tyrosine 486 leads to rapid nuclear export of Bach1 that allows Nrf2 to bind to the antioxidant response element and activate defensive gene expression. J. Biol. Chem., 285, 153-162 (2010).

57) Short J, Armstrong NB, Kolitsky MA, Mitchell RA, Zemel R, Lieberman I. Amino acids and the control of nuclear DNA replication in liver. Control of Proliferation in Animal Cells, 1, 37-38 (1974).
58) Hernandez-Munoz R, Diaz-Munoz M, López V, López-Barrera F, Yáñez L, Vidrio S, Aranda-Fraustro A, Chagoya de Sánchez V. Balance between oxidative damage and proliferative potential in an experimental rat model of CCl4-induced cirrhosis: protective role of adenosine administration. Hepatology, 26, 1100-1110 (1997).

59) Trejo-Solís C, Chagoya de Sánchez V, Aranda-Fraustro A, SánchezSevilla L, Gómez-Ruíz C, Hernández-Muñoz R. Inhibitory effect of vitamin $\mathrm{E}$ administration on the progression of liver regeneration induced by partial hepatectomy in rats. Lab. Invest., 83, 1669-1679 (2003). 